\title{
Parents' perceptions of disclosure of the diagnosis of cerebral palsy
}

\author{
G Baird, H McConachie, D Scrutton
}

\begin{abstract}
The aim of the paper is to propose guidelines for good practice in disclosing the diagnosis of cerebral palsy to parents. The guidelines draw on an interview study with parents of 107 children, average age 24 months, in the South East Thames region. In addition case notes were examined, and mothers completed questionnaires to measure current levels of depression and coping strategies. Dissatisfaction with how the diagnosis had been disclosed was greater where children had been premature and/or low birth weight, where they developed more severe degrees of physical disability, and where the diagnosis had been made later. Dissatisfaction was related to greater degrees of later self reported depression. The guidelines take account of the findings, in particular the need for early close liaison between neonatology and community paediatric services. Suggestions are made for how to ensure implementation and monitoring of good practice.
\end{abstract}

(Arch Dis Child 2000;83:475-480)

Keywords: cerebral palsy; patient satisfaction; early diagnosis; guidelines.

Guy's and St Thomas's NHS Trust, Newcomen Centre, Guy's

Hospital, 1 St Thomas

Street, London

SE1 9RT, UK

G Baird

Department of Child Health, University of Newcastle, The

Fleming Nuffield Unit, Burdon Terrace, Jesmond,

Newcastle-upon-Tyne

NE2 3AE, UK

$\mathrm{H}$ McConachie

Neurosciences Unit, Institute of Child Health and Paediatric Department, Guy's, King's College and St Thomas's Hospitals Medical and Dental Schools, King's

College, London, UK

D Scrutton

Correspondence to:

Dr Baird

Gillian.Baird@

gstt.sthames.nhs.uk

Accepted 13 July 2000
There are now many sources of advice available on how to give parents an early diagnosis of disability in their child. Numerous guidelines have been drawn up. ${ }^{1-6}$ There has been little evaluation of such guidelines, for example, whether they have been implemented, and whether they have an effect in increasing parents' satisfaction with the way that they have been told. However, Cunningham et al showed that a policy, carefully instituted and maintained, could reduce dissatisfaction to zero in parents of infants with Down's syndrome. ${ }^{7}$ They also noted that, after a staff changeover within the maternity unit studied, the policy partly lapsed and dissatisfaction was again expressed by some parents.

Our aim is to discuss guidelines for good practice in disclosing the diagnosis of cerebral palsy to parents. The impetus arises from continuing research evidence that, when interviewed, around half of parents of children with physical disability express dissatisfaction with the way that disclosure was handled. ${ }^{8-10}$ There are several aspects of the nature of cerebral palsy as a diagnosis that may make procedures particularly difficult to follow in a consistent manner. For example, the diagnosis is an "evolutionary" one: the child's motor disorder changes over the first year of life, and early signs are not necessarily predictive of later motor disorder. Many children who develop cerebral palsy have spent time in a special care baby unit (SCBU), but only a proportion of children cared for in SCBU will go on to develop motor disorder. A further complication is the involvement of a variety of paediatric staff with such children: their care may remain with a consultant neonatologist, or may pass from the neonatologist to community paediatrics at an early stage; other children with cerebral palsy present first with parental concerns to their general practitioner, local baby clinic, health visitor, or others.

\section{Population based study of bilateral} cerebral palsy

A total population cohort of children with bilateral cerebral palsy was identified in the South East Thames region; that is, all children with possible bilateral cerebral palsy (including those with profound intellectual impairment, or general delay such that a motor disorder might be part of the pathology) born between January 1989 and December 1992 were notified to one of the authors (DS) by the paediatricians and physiotherapists of all districts in the South East Thames region of the UK. Children with hemiplegia were seen to check that they did not have a bilateral functional disability. The main focus was to examine hip joint development, so the study is longitudinal, with continuing contact between researchers and local professionals, allowing confidence that as full ascertainment as possible has been achieved. A total of 660 children were referred to the study. Of those with cerebral palsy, 346 had a confirmed diagnosis of a bilateral motor disorder at age 5 years, a prevalence estimate of 1.7 per 1000 live births ${ }^{11}$; an additional 84 children with hemiplegia were seen.

We report interviews with parents of children with confirmed cerebral palsy (including hemiplegia) who were seen by a consultant developmental paediatrician (GB) when they were around 24 months of age. We present data concerning parents' satisfaction with the manner of disclosure, as reflecting recent practice in an area with good intraregional professional links and services to families of disabled children. We discuss parents' recommendations on how professionals should practice.

\section{Methods}

SUBJECTS

The parents of the first 180 children referred into the study, born in 1989 and 1990, were interviewed (by GB). We report results in the 107 children who met the following inclusion criteria. 
Table 1 Child characteristics $(n=107)$

\begin{tabular}{llll}
\hline & $n$ & $\%$ & \\
& & & \\
Gender & 46 & 43.0 & \\
Female & 61 & 57.0 & \\
Male & & & \\
Severity of physical disability & 31 & 29.0 & \\
Mild or hemiplegia & 32 & 29.9 & \\
Moderate & 44 & 41.1 & \\
Severe & & & \\
Additional learning disability & 47 & 43.9 & \\
None & 29 & 27.1 & \\
Mild/moderate & 31 & 29.0 & \\
Severe/profound & & & \\
Birth weight & 22 & 20.6 & \\
Below 1500 g & 18 & 16.8 & \\
1500-1999 g & 13 & 12.1 & \\
2000-2499 g & 54 & 50.5 & \\
2500+ g & & & \\
Known cause for cerebral palsy & 50 & 46.7 & \\
Yes & 57 & 53.3 & \\
No & Mean & SD & Range \\
& 35.50 & 5.33 & $24-43$ \\
Gestational age (weeks) & 10.08 & 6.05 & $0-36$ \\
Age at diagnosis (months) & 23.88 & 6.04 & $14-40$ \\
Age at interview (months) & & & \\
\hline
\end{tabular}

Table 2 Parent characteristics $(n=106)$

\begin{tabular}{|c|c|c|c|}
\hline & $n$ & $\%$ & \\
\hline \multicolumn{4}{|l|}{ Ethnic background } \\
\hline White British & 95 & 89.6 & \\
\hline One or both parents & 10 & 9.4 & \\
\hline Other background (missing) & 1 & 0.9 & \\
\hline \multicolumn{4}{|l|}{ Mother employed } \\
\hline Yes & 28 & 26.4 & \\
\hline No & 78 & 73.6 & \\
\hline \multicolumn{4}{|l|}{ Maternal education } \\
\hline Secondary & 58 & 54.7 & \\
\hline Further education & 44 & 41.5 & \\
\hline Missing & 4 & 3.8 & \\
\hline \multicolumn{4}{|l|}{ Pursuing litigation } \\
\hline Yes & 16 & 15.1 & \\
\hline No & 84 & 79.2 & \\
\hline \multirow[t]{2}{*}{ Missing } & 6 & 5.7 & \\
\hline & Mean & $S D$ & Range \\
\hline Mother age at birth (years) & 27.83 & 5.27 & $17-42$ \\
\hline Father age at birth (years) & 30.59 & 7.27 & $20-57$ \\
\hline Edinburgh Depression Scale & 9.60 & 4.13 & $2-26$ \\
\hline Ways of Coping Inventory & 135.49 & 23.17 & $\begin{array}{l}83-200 \\
(\mathrm{n}=75)\end{array}$ \\
\hline
\end{tabular}

- Confirmed diagnosis of cerebral palsy at time of interview, agreed between the two researchers

- A primary diagnosis of cerebral palsythat is, not profound and multiple learning difficulties.

Children were excluded for the following reasons.

- Cerebral palsy acquired from postnatal cause (for example, meningitis)

- Where the likelihood of problems was obvious at birth (for example, microcephaly)

- The child was fostered.

Two children were twins, with differing patterns of cerebral palsy and of parental satisfaction; data on both children are presented but the data for parent characteristics are presented only once. Table 1 presents the children's characteristics and table 2 the parents' characteristics.

MEASURES AND PROCEDURE

Dr Baird visited families in their homes for a semi structured interview with mothers (and fathers if available). The parents were asked about "disclosure"-that is, the occasion of confirmation of diagnosis. Specific questions were asked about aspects of structure (who was present, both parents or only one, who gave the news, where the interview was carried out, etc), manner (whether the person showed both empathy and conveyed warmth, was honest, etc), and information (focusing on whether enough information about the diagnosis or condition was given, whether it was easy to understand, and whether other information should have been or was given), and what they would have liked to happen. The interviewer then rated the overall level of satisfaction expressed by parents for each of these aspects on a four point scale, and checked with parents that her received view was agreed by them.

The interview also included questions about current problems in caring for the child, hospital admissions, family circumstances, and other matters not reported in this paper. Family demographic variables (for example, maternal education and employment status, parental ethnicity) were ascertained, and mothers completed two questionnaires to measure current levels of depression (Edinburgh Postnatal Depression Scale ${ }^{12}$ ) and coping (Ways of Coping Inventory $\left.{ }^{13}\right)$. The depression scores are presented as a continuous measure, not as above/below cut off for depression, as the cut off points have been developed for use where the scale is given within weeks after birth, rather than in the infant's second year of life.

At the home visit, each child was examined by GB, and level of severity of physical disability and intellectual impairment assessed. From the children's medical notes, with parental permission, GB extracted information on birth weight, gestational age, causation of cerebral palsy, and date of confirmation of diagnosis.

ANALYSIS

The results on ratings of satisfaction are presented, and relationship with child and family characteristics explored using $\chi^{2}$ and $t$ tests (that is, satisfied versus dissatisfied).

\section{Results}

OVERALL SATISFACTION

Parents of three children reported that no diagnosis had been given and so they could not comment on "disclosure". A further three parents reported that nobody had told them directly (for example, one had found out by reading the child's medical notes, one had received a letter from the social services disability worker, and one had read the diagnosis first in a letter from the local public housing authority) and thus they could only comment on the type of information that had been made available to them.

Table 3 shows the number and percentage of mothers rated at each level of satisfaction with the structure and manner of the disclosure and with the information given. Three quarters were satisfied or very satisfied with the structure and manner of telling, but satisfaction with the information content was lower (54\%).

The great majority of mothers were told by a consultant $(89,83 \%)$. Four were told first after referral to a tertiary centre, and four by a 
Table 3 Mother's degree of satisfaction with disclosure $(n=107)$

\begin{tabular}{|c|c|c|c|c|c|c|}
\hline & \multicolumn{2}{|c|}{ Structure } & \multicolumn{2}{|c|}{ Manner } & \multicolumn{2}{|c|}{ Information } \\
\hline & $n$ & $\%$ & $n$ & $\%$ & $n$ & $\%$ \\
\hline Very satisfied & 4 & 3.7 & 28 & 26.2 & 24 & 22.4 \\
\hline Satisfied & 76 & 71.0 & 48 & 44.9 & 34 & 31.8 \\
\hline Dissatisfied & 20 & 18.7 & 18 & 16.8 & 37 & 34.6 \\
\hline Very dissatisfied & 1 & 0.9 & 7 & 6.5 & 9 & 8.4 \\
\hline Missing ${ }^{\star}$ & 6 & 5.6 & 6 & 5.6 & 3 & 2.8 \\
\hline
\end{tabular}

^No diagnosis (3) or not told in person (3).

physiotherapist. Most parents reported that they had suspected all was not right before being told the diagnosis $(92,86 \%)$ and in only 15 cases had a professional been the first to notice. Forty four of the mothers said they had been angry at the delay in being given a diagnosis after they had mentioned their suspicions.

We should have been told earlier. Ideally you want to know all the facts. The small head circumference matters to me even if the doctors say "don't bother about it".

Nobody believed me. I should have been told when the GP knew.

FACTORS RELATED TO SATISFACTION

Table 4 gives significance levels of associations between child and parent variables and levels of satisfaction. Satisfaction was related to a number of child variables, indicating lower satisfaction where the baby had been born prematurely (for example, mean gestational age of babies whose mothers were satisfied with the structure of the telling $=36.3$ weeks, dissatisfied $=33.2$ weeks) and at lower birth weight. Satisfaction was also lower where children developed more severe degrees of physical disability: $67.2 \%$ of parents of children with mild or moderate physical disability were satisfied with the information received in contrast with $39.5 \%$ of parents of children with severe disability. This relation tended also to apply where children had additional learning disabil- ity $(68.2 \%$ of parents of children with no learning disability were satisfied with the information received in contrast with $46.7 \%$ of parents of children with additional learning disability). Finally, there was a consistent trend for parents of children diagnosed later to be more dissatisfied (for example, mean age at diagnosis of children whose parents were satisfied with the manner of the telling $=8.8$ months, dissatisfied $=11.1$ months).

Of the parental variables, there was a consistent trend for younger parents to be more dissatisfied (for example, mean age of father at birth where parents were satisfied with the manner of the telling $=31.6$ years, dissatisfied $=27.7$ years; mean age of mother was 28.3 years and 26.4 years respectively). Demographic variables such as maternal education and employment were not related, but parents' ethnicity was. Of families in which one or more parent described themselves as other than "white British", more than half were dissatisfied with all three aspects of disclosure.

We looked at variables which may indicate effects of experiences around disclosure of diagnosis. There was no relation between levels of satisfaction and current ways of coping, but there was a consistent trend for dissatisfaction to be related to current level of depression (for example, mean depression score of mothers satisfied with the structure of the telling $=8.9$, dissatisfied $=11.9$ ). Finally, there was a clear relation between dissatisfaction and parents taking legal action: for example, of the 46 parents who were dissatisfied with the information they had received, 12 were known to be suing ( $26.1 \%$, as opposed to $5.2 \%$ of those who said they were satisfied).

\section{PARENTS' COMMENTS}

Parents made a number of comments during the interviews about the structure and manner of the telling, and the information made available, which substantiate the guidelines to be suggested below.

Table 4 Variables related to satisfaction with disclosure

\begin{tabular}{|c|c|c|c|c|}
\hline & \multicolumn{3}{|l|}{ Level of significance } & \multirow{2}{*}{$\begin{array}{l}\text { More } \\
\text { satisfied if: }\end{array}$} \\
\hline & Structure & Manner & Information & \\
\hline \multicolumn{5}{|l|}{ Child variables } \\
\hline Gender & NS & NS & NS & \\
\hline Severity of physical disability & NS & NS & $\chi^{2} 9.08$, df $2, p=0.01$ & Less severe \\
\hline Additional learning disability & NS & NS & NS & \\
\hline $\begin{array}{l}\text { Birth weight }(<2500 \mathrm{~g} \text { and } \\
>2500 \mathrm{~g})\end{array}$ & $\chi^{2} 8.13$, df $1, p<0.01$ & NS & NS & Greater \\
\hline Known cause for cerebral palsy & NS & NS & NS & \\
\hline Gestational age & $\begin{array}{l}t-2.45, \mathrm{p}<0.02 \\
(95 \% \mathrm{CI}-5.65,-0.60)\end{array}$ & NS & NS & Greater \\
\hline Age at diagnosis & NS & $\begin{array}{l}t 2.02, \mathrm{p}<0.05 \\
(95 \% \mathrm{CI} 0.04,4.51)\end{array}$ & NS & Lower \\
\hline Mother employed & NS & NS & NS & \\
\hline Maternal education & NS & NS & NS & \\
\hline Mother age & NS & NS & NS & \\
\hline Father age & NS & $\begin{array}{l}t-3.06, \mathrm{p}<0.01 \\
(95 \% \mathrm{CI}-6.53,-1.38)\end{array}$ & NS & Higher \\
\hline Postnatal depression score & $\begin{array}{l}t 2.88, \mathrm{p}<0.01 \\
(95 \% \text { CI } 0.92,4.98)\end{array}$ & NS & NS & Lower \\
\hline Current ways of coping & NS & NS & NS & \\
\hline
\end{tabular}

For "ethnic background" and "pursuing litigation" see text. 
There should be separate ward facilities [for parents] if your baby is in special care.

I was told bluntly, on my own, with no consideration for my feelings. I would have preferred a more gentle introduction.

We were told at six months. It seemed blunt but there was opportunity to go back a week later. I wanted to meet another mother but was advised not to. The physio found one-she was the best thing and the greatest help.

We saw the consultant, and were told cerebral palsy, because my mum asked what the problem was. Then we were sent out and had to ask the sister what it was.

I wanted more help when he was discharged from the premature baby unit-nobody told me how difficult it would be. I wanted to meet other parents. (mother of three)

We weren't given enough information about allowances or parent groups or other developmental centres.

At the hospital there should be counselling, and then immediate handover to someone who can help you to do something.

\section{Discussion}

The picture gained through these interviews is a mixed one, representing both good and bad practice in the often complex process of confirming and disclosing a diagnosis of cerebral palsy to the parents. The children represented in the current study were born more recently than in comparable studies. Gough et al found that half of the parents of Scottish children with cerebral palsy (born between June 1985 and May 1986) were dissatisfied with the disclosure, ${ }^{8}$ and Sloper and Turner's study of physically disabled children aged 6 months to 13 years, conducted in $1988 / 89$, found $51 \%$ dissatisfied (with $37 \%$ satisfied and $12 \%$ neither satisfied nor dissatisfied). ${ }^{10}$ Thus, it may appear that overall the satisfaction level with disclosure interviews has increased compared with previous studies. Sloper and Turner gained a similar impression in their study by comparing those parents told some years before with those told more recently. However, it is necessary to be cautious in this interpretation given differences in method, such as the identity of the interviewer (a research worker in previous studies, a clinician in the present study) and the format for rating satisfaction (one out of five levels written on a card in the two studies cited above, a summary rating by the interviewer in the present study).

Aspects of structure of the disclosure interview, of the manner of the person doing the telling, and of the information given to parents at the time were all related significantly to various child variables. Dissatisfaction with the manner of the telling was significantly related to the age at which diagnosis was given; on further probing it became clear that dissatisfaction was frequently expressed because of perceived disbelief on the part of professionals in reaction to parental concerns, or delay accompanied by the feeling that "everyone knew before I did". Where a firm diagnosis cannot be given, Cottrell and Summers ${ }^{1}$ have noted that parents can accept the reasons, as long as they are kept informed. The area where we found the greatest difficulty seemed to be neonatal follow up clinics, especially for premature (and/or low birthweight) babies. A number of parents indicated that they were glad to have been, or would have liked to have been warned of possible adverse outcomes from prematurity. Children attending neonatal follow up clinics are frequently seen by junior staff, who may not be experienced in evaluating infant development. Recent research suggests that failure to achieve successive motor milestones is a good predictor of cerebral palsy in premature babies. ${ }^{14}$

There are indications in the data of other circumstances in which improvements in practice are required. For example, all aspects of practice need to be reviewed in support of families with an ethnic minority background. ${ }^{15}$ Furthermore, the consequences of dissatisfaction with disclosure are a matter for debate. One study of children with intellectual disability $^{16}$ found that parental acceptance of the diagnosis was related to the observed degree of clarity and frankness of the professional consultation, rather than to child or parent characteristics. Sheehan et al, in a study of young children with a neurological diagnosis (three quarters with cerebral palsy), have further found that mothers who have unresolved feelings in relation to their child's diagnosis have higher degrees of self reported stress. ${ }^{17}$ Our study supports a link between dissatisfaction with disclosure of diagnosis and later self reported depression (without disentangling direction of effect). However, Sloper and Turner ${ }^{18}$ studied parents of children with a variety of conditions associated with physical disability, and suggested that satisfaction with disclosure was not a major determinant of long term satisfaction with life and adaptation to the child. They also found no relationship with mothers' current coping strategies, which is replicated in the present study. Their sample did, however, include children with a range of intervals since diagnosis (6 months to 8.5 years) and thus the majority of parents would have had many events and issues to come to terms with over time. An unexpected finding of the current study was the number of parents who were actively pursuing litigation against the NHS Trust (hospital) where their baby had been born. Some commented that they were doing this in order to find out more information, which they felt had been kept from them.

Parents made a number of comments about what they had found helpful, and suggestions 


\section{Guidelines on disclosure of diagnosis}

PEOPLE

Consultant paediatrician

Member of the continuing care team

Both parents

Infant present

ENVIRONMENT

Private place, uninterrupted

Privacy for parents afterwards

CONTENT

Direct, clear information

Manner-honest, warm, sympathetic

FOLLOW UP

Opportunity for further interview soon

Letter summarising the discussion

Information re premature babies

Information re cerebral palsy

Information re local services

Offer introduction to another parent

Offer to talk to other family members

of what could be done better. Almost all mentioned the need for a booklet on benefits, and that they found written information helpful. The SCOPE helpline and information pack were often mentioned as a good resource. Rapid follow up by a physiotherapist was needed, and where a further appointment had been offered to talk through the diagnosis, this was valued.

\section{Implications}

RECOMMENDATIONS FOR GOOD PRACTICE

These are summarised below and draw heavily on Cunningham and the North Western Regional Health Authority resource booklet, ${ }^{25}$ adapted for the complexity of the diagnosis of cerebral palsy. Disclosure of diagnosis requires professionals to plan ahead, so that the appropriate environment, people, information, and immediate follow up support can be in place (see summary box).

People

(1) In most cases the diagnosis of cerebral palsy should be conveyed by a consultant paediatrician, if possible accompanied by a health visitor or physiotherapist who will be involved in the child's continuing care.

(2) There should be no junior medical persons present unless they have a clear role in future care. Arrangements for training of staff should not include direct observation.

(3) Parents should be told together. If this means putting off the discussion to a further clinic, then there should be acknowledgement of some problems which require further observation and discussion, this being given as the reason for the importance of both parents attending the next appointment. Where a parent is single, the suggestion of bringing another family member should be made.

(4) The infant should be present (except if very ill and still in special care).
(5) If necessary, an interpreter should be present. Great caution should be exercised before assuming that another member of the family should take this role.

\section{Environment}

(6) Parents should be told in a private place where the consultation will be undisturbed.

(7) There should be the possibility for parents to remain in the room in privacy immediately after the interview.

(8) Mothers who have a sick child in special care should be offered the chance to move into a private room in the postnatal ward.

Content

(9) Parents should be told directly, with clarity about medical details, and parents given as much time as they wish to ask questions. In the case of cerebral palsy, many parents feel a strong need to understand the reason why their child has impairments. Many parents interviewed expressed the feeling that the doctor was hiding something.

(10) The manner of the professional who delivers the diagnosis is very important, and should reflect sympathy, honesty, and openness. Parents ask for a balanced viewpoint, rather than a catalogue of possible problems.

Follow up

(11) Parents should be offered the chance to discuss the diagnosis again very shortly after disclosure, with the professionals present at the original interview.

(12) The parents should be provided with written information based on the content of the disclosure interview. This should be carefully written to be understood, and to contain some optimistic points in the history and prognosis. A mention should be made of early support programmes. Parents would very much appreciate a contact name and telephone number which they can use for support, preferably for one of the staff whom they already know.

(13) There should be very early referral to a community physiotherapist, to give developmental support to the child and parents. This may well have been initiated before a conclusive diagnosis has been made. Where referral is made before diagnosis, the physiotherapist should be empowered to discuss a range of possibilities for diagnosis in response to parents' questions, and should notify the consultant paediatrician of the need for a diagnostic interview.

(14) Information should be provided, probably in the form of leaflets about the problems which may occur with premature babies, for example, in terms of difficulties in feeding, sleeping, and irritability. Some guidelines on how to care for a small and vulnerable baby will be helpful. 
Parents also need to know what to expect at neonatal clinics.

Once a firm diagnosis is made, then parents would appreciate general information about the condition, about the feelings which other parents may have had at such a time, about support groups, and about the range of services which may be available in their locality. ${ }^{19}$ At the time of disclosure of diagnosis, parents are likely to feel very anxious and vulnerable, and confused about their expectations for the baby's future. It is important to try to offer choice to parents, so as to leave them some control over what is happening in their lives. One example might be to provide alternatives in the way that physiotherapy is offered, either in the family's own home, or at a centre where they can meet other parents. Parents have very variable and individual reactions at this early stage.

(15) An offer should be made for arranging introduction to another parent of a similar child with similar difficulties. Ideally that parent should have received some training in befriending, and have continuing support available.

(16) The professionals who have given the diagnostic information should offer to talk to other family members, if the parents wish this.

\section{Getting guidelines into practice}

In the introduction, we referred to problems in putting guidelines into practice, particularly in the case of the diagnosis of cerebral palsy. It is important that local professionals are brought into a relationship of working together, with mutual respect.

(1) Structure and content of neonatal follow up. Community paediatricians should be involved at a very early stage in neonatal follow up clinics. The neonatologist can follow up the physical progress of the child, but can quickly involve their local colleague when developmental signs become apparent. Practice in the USA has indicated that diagnosis is enhanced by using an approach based on motor milestones. ${ }^{14}$

(2) Working group. The likelihood of implementing guidelines will be enhanced if a local group is formed to develop a workable policy. Involvement in drawing up such a policy creates a commitment to carrying it out.

(3) Audit. There also needs to be a commitment to monitoring the implementation of the policy, and auditing its success. For example, interviews with parents every three years or so can be used to audit various aspects of procedure. The evaluation should be conducted by somebody not involved in the early services.

(4) Staff training is an important aspect of policy development and implementation of guidelines. One of the obstacles to progress may be the attitude of some senior professionals that "I know how to break the news". Certainly, most health professionals are caring people, trying under pressure to do their best, and many studies indicate greater satisfaction with the manner of the telling than with other aspects. However, no harm can come from reviewing one's own practice. Community paediatricians may find that they need extra training in early evaluation of premature babies. Neonatologists may come to recognise their need for training in the management of disclosure, and in ensuring effective early support to families. The topics for training could include: reasons why it is important to break news well; society's attitudes towards disability and the likely influence of these attitudes on parents and staff; understanding parents' reactions; principles of counselling; the importance of having available appropriate written information; reviewing one's own difficulties in breaking bad news; roles of different staff members; cultural and religious implications; introduction to services and resources available; and procedures for maintaining and monitoring implementation of guidelines. $^{5}$

1 Cottrell DJ, Summers K. Communicating an evolutionary diagnosis of disability to parents. Child: Care, Health and Development 1990;16:211-18.

2 Cunningham CC. Telling parents their child has a disability. In: Mittler P, Mittler H, eds. Innovations in family support for people with learning disabilities. Chorley, Lancashire: Lisieux Hall, 1994

3 Duffy T. Focus on children with special needs: a guide to good practice for professionals working with children with special needs. Sevenoaks, Kent: Management Focus, 1994.

4 Jupp S. Making the right start: a practical manual to help break the news to families when their baby has been born with a disbility. Hyde, Cheshire: Opened Eye Publications, 1992.

5 North Western Regional Advisory Group for Learning Disability Services. Breaking the news: a resource for developing guidelines of good practice, procedures and training in informing parents of diagnosis of a child's impairment. Calderstones, Blackburn: North Western Regional Health Authority,

6 SCOPE. Right from the start: sharing the news. Campaign News, Winter/Spring. SCOPE, 12 Park Crescent, London News, Winter/Spring

7 Cunningham CC, Morgan PA, McGucken RB. Down's syndrome: is dissatisfaction with disclosure of diagnosis syndrome: is dissatisfaction with disclosure of
inevitable? Dev Med Child Neurol 1984;26:33-9.

8 Gough D, Li L, Wroblewska A. Services for children with a motor impairment and their families in Scotland: final report to the Scottish Office Education and Home and Health Departments. Glasgow: University of Glasgow, Public Health Research Unit, 1993.

9 Quine L, Rutter, DR. First diagnosis of severe mental and physical disability: a study of doctor-parent communication. F Child Psychol Psychiatry 1994;35:1273-87.

10 Sloper P, Turner S. Determinants of parental satisfaction with disclosure of disability. Dev Med Child Neurol 1993;35:816-25.

11 Scrutton D, Baird G. Surveillance measures of the hips of children with bilateral cerebral palsy. Arch Dis Child 1997; 56:381-4.

12 Cox JL, Holden JM, Sagovsky R. Detection of post-natal depression: development of the 10-item Edinburgh Postnadepression: development of the 10-item Edinburgh Post
tal Depression Scale. Br F Psychiatry 1987;150:782-6.

tal Depression Scale. Br f Psychiatry 1987;150:782-6.
13 Knussen C, Sloper P, Cunningham C, Turner S. The use of the Ways of Coping (Revised) Questionnaire with parents the Ways of Coping (Revised) Questionnaire with parents of children

14 Allen MC, Alexander GR. Using motor milestones as a multistep process to screen preterm infants for cerebral palsy. Dev Med Child Neurol 1997;39:12-16.

15 Shah R. The silent minority: children with disabilities in Asian families. London: National Children's Bureau, 1992.

16 Svarstad BL, Lipton HL. Informing parents about mental retardation: a study of professional communication and parent acceptance. Soc Sci Med 1977;11:645-51.

17 Sheehan T, Marvin RS, Pianta RC. Mothers' resolution of their child's diagnosis and self-reported measures of parenting stress, marital relations, and social support. $\mathcal{f}$ Pediatr Psychol 1997;22:197-212.

18 Sloper P, Turner S. Risk and resistance factors in the adaptation of parents of children with severe physical disability. tation of parents of children with severe physi
f Child Psychol Psychiatry 1993;34:167-88.

19 Donovan TJ, Reddihough DS, Court JM, Doyle LW. Health literature for parents of children with cerebral palsy. Dev Med Child Neurol 1989;31:489-93. 